\title{
ENRAIZAMENTO DE DIFERENTES TIPOS DE ESTACAS DE OLIVEIRA (Olea europaea L.) UTILIZANDO ÁCIDO INDOLBUTÍRICO
}

\author{
Rooting of different types of olive (Olea europaea $\mathrm{L}$.) tree cuttings using indol butyric acid
}

\author{
Rafael Pio ${ }^{1}$, Débora Costa Bastos ${ }^{2}$, Amélio José Berti ${ }^{3}$, João Alexio Scarpare Filho ${ }^{4}$, \\ Francisco de Assis Alves Mourão Filho ${ }^{4}$, Fábio Albuquerque Entelmann ${ }^{5}$, \\ André Siqueira Rodrigues Alves ${ }^{5}$, José Emílio Bettiol Neto ${ }^{6}$
}

\begin{abstract}
RESUMO
O presente trabalho foi realizado com o objetivo de avaliar a influência do número de pares de folhas e testar o efeito de diferentes concentrações de AIB (ácido indolbutírico) no enraizamento de estacas semilenhosas de oliveira. O delineamento experimental utilizado foi o inteiramente casualizado, em fatorial 4 x 3, sendo quatro concentrações de AIB $\left(0,1000\right.$, 2000, e $\left.3000 \mathrm{mg} \mathrm{L}^{-1}\right)$ e três tipos de estacas (sem folhas, com um par de folhas e com dois pares de folhas). As estacas foram padronizadas com $12 \mathrm{~cm}$ de comprimento. Após o preparo inicial, as estacas foram imersas nas soluções de AIB por cinco segundos e, em seguida, colocadas em bandejas de polipropileno contendo o substrato Plantmax ${ }^{\circledR}$ e transportadas para casa-de-vegetação, com umidade e temperatura controladas, onde permaneceram por 90 dias. As variáveis analisadas foram: porcentagem de estacas enraizadas e brotadas, número de folhas, brotos e raízes emitidas por estaca e comprimento médio das brotações e das raízes. O AIB apenas promoveu influência ao sistema radicular; a concentração de $2000 \mathrm{mg} \mathrm{L}^{-1}$ de AIB promoveu maior enraizamento e a concentração de $3000 \mathrm{mg} \mathrm{L}^{-1}$ de AIB em estacas com dois pares de folhas promoveu melhores resultados para número de raízes por estacas e comprimento médio das raízes; estacas ausentes de folhas favoreceram maior brotação nas estacas.
\end{abstract}

Termos para indexação: propagação, estaquia e AIB.

\section{ABSTRACT}

The present work was developed with the objective to evaluate the influence of the number of leaves and test the effect of different concentrations of IBA (indolbutyric acid) in the cutting propagation of olive tree. The experimental design was complete randomized, in a two factors arrangement $(4 \times 3)$, with four different concentrations of IBA $(0,1000,2000$ and 3000 $\mathrm{mg} \mathrm{L}^{-1}$ ) and three different types of cuttings (without leaves, one pair of leaves and two pairs of leaves). The cuttings were padronized with $12 \mathrm{~cm}$ of length and treated with IBA for five seconds. After that, they were taken to polysty rene trays filled with Plantmax ${ }^{\circledR}$ and stayed under house green conditions for 90 days. Rooting and sprouting percentage, number of leaves, sprouts and roots, sprout and root length were evaluated. IBA only influenced the root system; the concentration of $2000 \mathrm{mg} \mathrm{L}^{-1}$ promoted best results for rooting percentage and the concentration of $3000 \mathrm{mg} \mathrm{L}^{-1}$ IBA in cuttings with two pairs of leaves promoted best results for number of roots and root length; cuttings of absent leaves favored larger sprouting in the cuttings.

Index terms: propagation, cutting and IBA.

(Recebido para publicação em 4 junho de 2004 e aprovado em 16 de março de 2005)

\section{INTRODUÇÃO}

A oliveira (Olea europaea L.) pertence à família Oleaceae, na qual estão incluídos cerca de 30 gêneros, como o Fraxinus, Ligustrum, Syringa e Olea (GOBBATO, 1945). O cultivo de oliveiras adquiriu especial relevância em todo o mundo, pelo fato de o azeite de oliva ser comprovadamente benéfico à saúde humana, pela sua comprovada eficácia na proteção de enfermidades cardiovasculares e por ser muito utilizado como veículo na confecção de produtos farmacêuticos (OLIVEIRA, 2001).
O Brasil é um dos maiores importadores de produtos de oliveira da América do Sul, sendo a Argentina um dos maiores fornecedores, além da Espanha e Portugal (CASTRO et al., 1997). Mesmo com um mercado consumidor de azeitonas e azeite de oliva constante, não se conseguiu, até os dias de hoje, que a Olivicultura no Brasil se tornasse uma alternativa rentável e viável para os produtores, devido principalmente a manejos inadequados e falta de conhecimento de modernas técnicas de formação e condução dos pomares (OLIVEIRA, 2001).

\footnotetext{
1. Engenheiro Agrônomo, Dr.,Pesquisador Científico Centro APTA Frutas - Instituto Agronômico de Campinas-IAC - Av. Luiz Pereira dos Santos, $\mathrm{n}^{\circ}$ 1500 - Corrupira - 13214-820 - Jundiaí, SP.

2. Engenheiro Agrônomo, M.Sc., Doutorando do curso de Fitotecnia - Departamento de Produção Vegetal - USP/ESALQ.

3. Engenheiro Agrônomo - Núcleo de Produção de Mudas - CATI - São Bento do Sapucaí, SP.

4. Engenheiro Agrônomo, Dr. - Professor do Departamento de Produção Vegetal - USP/ESALQ - jascarpa@esalq.usp.br - famourao@esalq.usp.br

5. Graduando do curso de Engenharia Agronômica - Universidade de São Paulo - Escola Superior de Agricultura "Luiz de Queiroz" - USP/ESALQ

6. Engenheiro Agrônomo - Pesquisador Científico Centro APTA Frutas - Instituto Agronômico de Campinas-IAC.
} 
Apesar de os frutos de oliveira possuírem sementes viáveis, a reprodução sexual não é desejada no estabelecimento de plantios comerciais, em razão de as plantas obtidas serem distintas da planta-mãe e apresentarem longo período juvenil. Sendo assim, a propagação vegetativa vem a ser a técnica mais viável para o processo de formação de mudas, mantendo, assim, as características genéticas das plantas-matrizes, uniformidade, porte reduzido e precocidade de produção (FACHINELLO et al., 1995; HARTMANN et al., 2002; PASQUAL et al., 2001). No caso da oliveira, a propagação por enxertia é limitada pela falta de estudos sobre a melhor combinação entre enxerto/portaenxerto, tanto do mesmo gênero como gêneros afins, sendo a estaquia a forma mais utilizada no processo propagativo dessa cultura (JACOBONI et al., 1976; OLIVEIRA, 2001).

A estaquia é um método de propagação muito utilizado, sendo sua viabilidade dependente da capacidade de formação de raízes, da qualidade do sistema radicular formado e do desenvolvimento posterior da planta propagada por esse método na área de produção. Pode-se classificar os fatores que afetam o enraizamento em fatores internos ou endógenos, considerando, principalmente, as condições fisiológicas e idade da planta-matriz, época de coleta da estaca, potencial genético de enraizamento, sanidade, balanço hormonal, oxidação de compostos fenólicos e posição da estaca no ramo; e fatores externos ou exógenos, como a temperatura, luz, umidade e substrato (FACHINELLO et al., 1995). Os fatores endógenos constituem um dos mais sérios problemas, sendo importante a busca de técnicas auxiliares, como o uso de reguladores de crescimento, para assim proporcionar uma melhoria do enraizamento (BIASI, 1996; MAYER, 2001). O grupo de reguladores de crescimento usado com maior freqüência na indução de enraizamento é o das auxinas (HINOJOSA, 2000). É necessário que haja um balanço hormonal entre promotores e inibidores do processo de iniciação radicular. A maneira mais comum de promover esse equilíbrio é pela aplicação exógena de reguladores de crescimento sintéticos, como o ácido indolbutírico (AIB), que podem elevar o teor de auxina no tecido (PASQUAL et al., 2001).

O método tradicional de enraizamento de estacas de oliveira é o enraizamento direto na cova de plantio, utilizando-se estacas de $60 \mathrm{~cm}$ de comprimento e de 5 a $10 \mathrm{~cm}$ de diâmetro. Devido ao tamanho do propágulo, a obtenção de novas plantas, utilizando estacas com esse padrão, requer grande quantidade de material propagativo, não assegurando, na maioria dos casos, a identidade sanitária da nova planta (CABALLERO \& DEL RIO, 1998). Sendo assim, o enraizamento de estacas em ambiente controlado vem a ser a alternativa mais recomendável para a oliveira. Porém, os resultados encontrados na literatura não são muito satisfatórios, a exemplo do trabalho de Oliveira (2001), que obteve $44,28 \%$ de estacas enraizadas de oliveira 'Ascolano 315', quando coletadas no mês de fevereiro e 16,64\% de enraizamento no mês de abril. Negash (2003) estudou o enraizamento de estacas de oliveira-selvagem [Olea europaea subsp. cuspidata (Wall. ex. DC.) Ciffieri] e concluiu que essa pode ser propagada por estaquia, porém, os danos ocasionados na planta-matriz e o baixo enraizamento inviabilizam esse método. Já Sebastiani \& Tognetti (2004), trabalhando com o enraizamento de estacas das oliveiras 'Frantoio' e 'Gentile di Larino', concluíram que essas cultivares apresentam baixo enraizamento, mesmo utilizando 4000 $m g L^{-1}$ de AIB.

Em conseqüência da falta de informações que envolvem o enraizamento de estacas de oliveira, principalmente no Brasil, realizou-se o presente trabalho com o intuito de verificar o potencial de enraizamento de estacas de oliveira 'Grapollo' com diferentes números de folhas e concentrações de AIB.

\section{MATERIAL E MÉTODOS}

Estacas semilenhosas localizadas na porção mediana de ramos de oliveira 'Grapollo', com doze anos de idade, foram coletadas de plantas-matrizes localizadas no Núcleo de Produção de Mudas da CATI (Coordenadoria de Assistência Técnica Integral) de São Bento do Sapucaí-SP, no mês de outubro. As estacas foram protegidas com papel umedecido, colocadas em caixa de isopor e levadas para o Setor de Horticultura da Escola Superior de Agricultura "Luiz de Queiros", da Universidade de São Paulo - ESALQ/USP, Piracicaba$\mathrm{SP}$, onde foi instalado o ensaio.

As estacas foram padronizadas com $12 \mathrm{~cm}$ de comprimento e mínimo de três pares de gemas. Os tratamentos constituíram-se de estacas com um par, dois pares e ausentes de folhas, submetidas em imersões de cinco segundos em quatro concentrações de AIB, diluído com hidróxido de sódio (0, 1000, 2000 e 3000 $\mathrm{mg} \mathrm{L}^{-1}$ de água destilada), sendo aprofundadas quatro centímetros da base da estaca na solução, perfazendo, assim, um fatorial $3 \times 4$, com quatro repetições e oito estacas por parcela, totalizando 384 estacas. Após o preparo inicial, as estacas foram colocadas em bandejas de polipropileno de 72 células (capacidade de $120 \mathrm{~cm}^{3}$ 
PIO, R. et al.

por célula), contendo o substrato comercial Plantmax ${ }^{\circledR}$. As bandejas foram transferidas para câmara de nebulização intermitente (temperatura de $25 \pm 5^{\circ} \mathrm{C}$, UR média de $72 \%$, tempo de aspersão de 20 segundos em intervalos de 10 minutos).

Passados 90 dias, foram coletados os seguintes dados biométricos: porcentagem de estacas enraizadas e brotadas, número de folhas, brotos e raízes emitidas por estaca, comprimento médio das brotações e das raízes.

Os dados foram submetidos à análise de variância, as concentrações de AIB foram submetidas à análise de regressão. As médias foram comparadas pelo teste Scott-Knott, ao nível de 5\% de probabilidade (GOMES, 2000). As análises foram realizadas pelo programa computacional Sistema para Análise de Variância - SISVAR (FERREIRA, 2000).

\section{RESULTADOS E DISCUSSÃO}

De acordo com a análise estatística, ficou evidenciado que houve interação entre as concentrações de AIB e o número de folhas para as variáveis referentes ao sistema radicular (porcentagem de estaca enraizadas, número de raízes emitidas da estaca e comprimento médio das raízes) e diferença significativa entre o número de folhas para as variáveis porcentagem de estacas brotadas, número de brotos e folhas.

Tanto para estacas ausentes de folhas como para estacas com folhas, a concentração de $2000 \mathrm{mg} \mathrm{L}^{-1}$ promoveu os melhores resultados de enraizamento
(56,86\% para estacas ausentes de folhas, 52,98\% para estacas com um par de folhas e $45,81 \%$ para estacas com dois pares de folhas) (Figura 1).

Estacas de oliveira 'Ascolano 315' dotadas de dois pares de folhas apresentaram 44,28\% de enraizamento quando coletadas e postas para enraizar no mês de fevereiro e 16,64\% de enraizamento no mês de abril, todas tratadas com $3000 \mathrm{mg} \mathrm{L}^{-1}$ de AIB; entretanto, estacas do mesmo padrão, porém, sem receber tratamento com AIB, promoveram apenas 3,12\% e 1,04\% de enraizamento, respectivamente, coletadas nas duas épocas em questão (OLIVEIRA, 2001).

Por esses resultados, verifica-se a influência da época de coleta das estacas e da cultivar, o que deve ser mais estudado em oliveiras no Brasil. As melhores épocas para o enraizamento de estacas de oliveira em países do hemisfério Norte são aquelas que coincidem com o final do fluxo de crescimento anual (CABALLERO, 1981). No que se refere à época mais adequada na obtenção das estacas, há diferenças entre espécies; algumas enraízam melhor no início da primavera e outras desde a primavera até o início do outono (FACHINELLO et al., 1995). No presente trabalho, as estacas foram coletadas no mês de outubro, quando as plantas estavam no estágio fenológico de crescimento dos frutos e em pleno crescimento vegetativo. Assim, esse pode ser um fator que limitou o maior enraizamento das estacas, podendo ser que no final do período vegetativo o potencial de enraizamento seja maior, como sugere Caballero (1981).

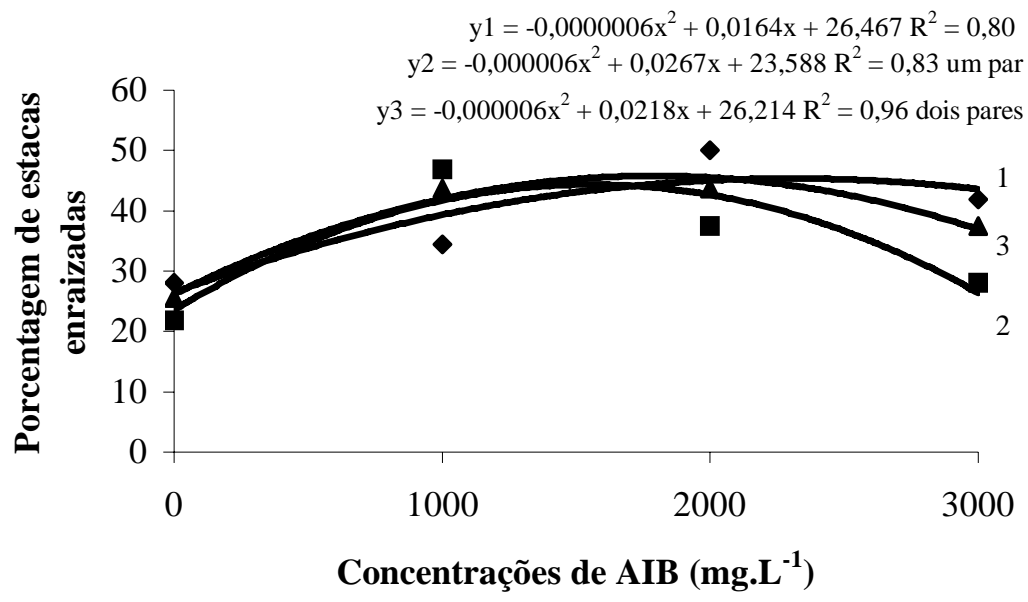

FIGURA 1 - Porcentagem de estacas enraizadas de oliveira ‘Grapollo’ em função de diferentes tipos de estacas e concentrações de AIB. ESALQ/USP, Piracicaba-SP, 2004.

Ciênc. agrotec., Lavras, v. 29, n. 3, p. 562-567, maio/jun., 2005 
De acordo com Munõz \& Valenzuela (1978), a influência da época do ano no enraizamento de estacas ocorre preferencialmente devido às variações no conteúdo dos cofatores presentes e à formação e acúmulo de inibidores do enraizamento. Hartmann et al. (2002) apontam que a época do ano em que se obtêm as estacas exerce influência significativa no enraizamento, podendo ser, inclusive, um fator decisivo para obtenção de êxito na propagação por estaquia.

Para o número de raízes emitidas por estacas, houve incrementos positivos, conforme se submeteram os diferentes tipos de estacas em concentrações crescentes de AIB, sendo a concentração de $3000 \mathrm{mg} \mathrm{L}^{-1}$ de AIB a que favoreceu o maior número de raízes emitidas por estaca (Figura 2). Pela mesma Figura, observa-se que houve 5,49 raízes emitidas em estacas ausentes de folhas, 5,54 em estacas com um par de folhas e 7,41 em estacas com dois pares de folhas. Para o comprimento médio das raízes, a concentração de $3000 \mathrm{mg} \mathrm{L}^{-1}$ de AIB promoveu melhores resultados
(Figura 3), com 6,30 cm de comprimento, em média, para estacas ausentes de folhas, $6,28 \mathrm{~cm}$ para estacas com um par de folhas e 12,11 para estacas com dois pares. Resultados semelhantes foram obtidos por Oliveira (2001), que obteve incrementos crescentes para o número de raízes por estacas e comprimento médio das raízes com concentrações crescentes de AIB.

Devido às respostas lineares para as variáveis número de raízes emitidas da estaca e comprimento médio das raízes, pressupõe-se que maiores concentrações venham a promover resultados superiores aos encontrados no presente trabalho. Outro indicio dessa suposição foi a elevada taxa de sobrevivência das estacas, não tendo ocorrido quase nenhuma morte das estacas durante a fase experimental, na qual as estacas permaneceram vivas, mas não enraizaram. Assim, outras concentrações de AIB devem ser testadas.

Em estacas ausentes de folhas, houve $75,71 \%$ de estacas brotadas, contra 32,91\% em estacas com um par de folhas e $24,28 \%$ em estacas com dois pares (Tabela 1).

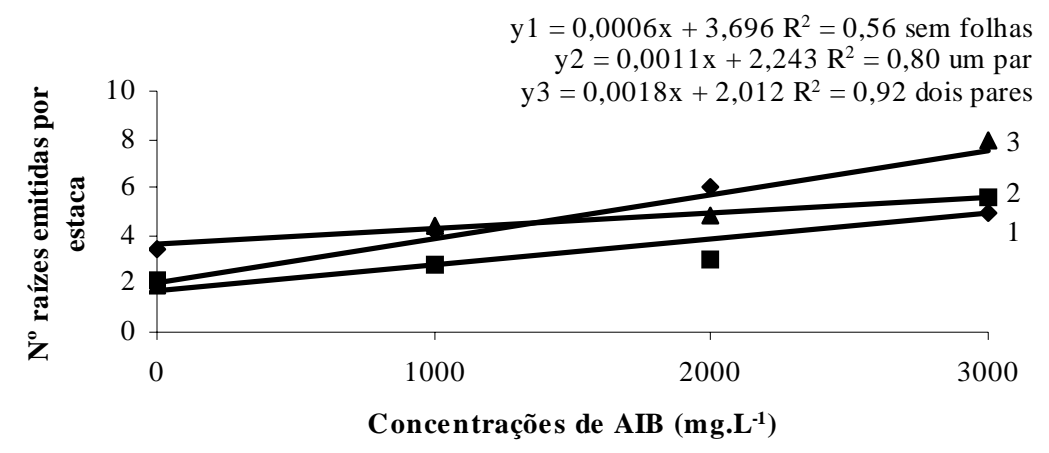

FIGURA 2 - Número de raízes emitidas por estaca de oliveira ‘Grapollo’ em função de diferentes tipos de estacas e concentrações de AIB. ESALQ/USP, Piracicaba-SP, 2004.

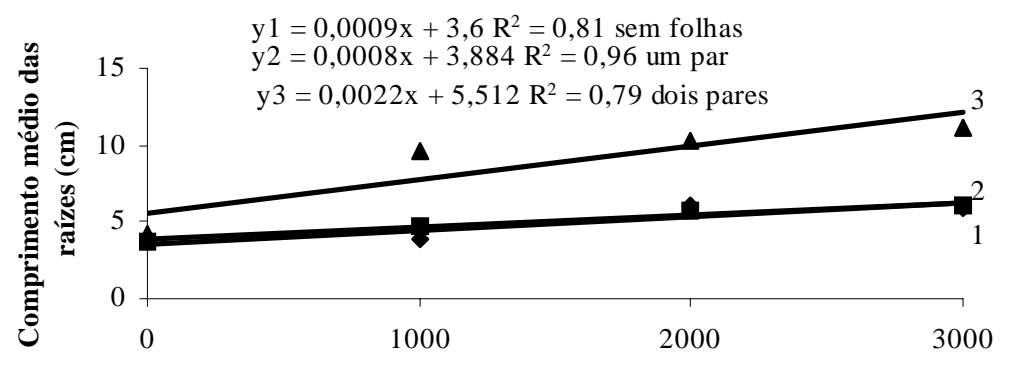

Concentrações de AIB (mg.L $\left.{ }^{-1}\right)$

FIGURA 3 - Comprimento médio das raízes de estacas de oliveira 'Grapollo' em função de diferentes tipos de estacas e concentrações de AIB. ESALQ/USP, Piracicaba-SP, 2004. 
TABELA 1 - Resultados médios da porcentagem de estacas brotadas (PEB), número de brotos (NB), número de folhas (NF) e comprimento médio das brotações (CMB, cm) em estacas de oliveira 'Grapollo', em função do número de folhas presentes na estaca. ESALQ/USP, Piracicaba-SP, 2004.

\begin{tabular}{lcccc}
\hline \multirow{2}{*}{ Tipos de estacas } & \multicolumn{4}{c}{ *Variável analisada } \\
\cline { 2 - 5 } & PEB & NB & NF & CMB \\
\hline Sem folhas & $75,71 \mathrm{a}$ & $1,86 \mathrm{a}$ & $7,55 \mathrm{a}$ & $1,57 \mathrm{a}$ \\
Um par de folhas & $32,91 \mathrm{~b}$ & $1,24 \mathrm{~b}$ & $3,59 \mathrm{~b}$ & $1,61 \mathrm{a}$ \\
Dois pares de folhas & $24,28 \mathrm{c}$ & $1,61 \mathrm{a}$ & $4,30 \mathrm{~b}$ & $1,35 \mathrm{a}$ \\
CV (\%) & 25,76 & 29,75 & 27,68 & 35,43 \\
\hline
\end{tabular}

* Médias seguidas da mesma letra na coluna não diferem significamente entre si pelo teste Scott-Knott ao nível de $5 \%$ de probabilidade.

Pela mesma Tabela, verifica-se ainda que estacas ausentes de folhas apresentaram maior emissão de folhas, em comparação aos demais tipos de estacas. Para o número de brotos, estacas ausentes de folhas e com dois pares apresentaram melhores resultados $(1,86$ e 1,61 brotos, respectivamente). A superioridade das características pertinentes à parte aérea em estacas ausentes de folhas pode estar relacionada ao fato de a remoção da folha ter promovido estímulo à brotação das gemas axilares localizadas na base do pecíolo da folha na estaca, onde essas se encontravam em dormência e, com a quebra da dominância, com a remoção das folhas da estaca, ocorreu maior emissão de brotos e folhas.

Em plantas que apresentam dominância apical extrema, somente a gema terminal se desenvolve, sendo as demais reprimidas; com a eliminação da porção de dominância, uma ou diversas gemas inferiores iniciam o crescimento. A supressão das demais gemas deve-se à auxina presente na gema dominante, que inibe o desenvolvimento das demais (GALSTON \& DAVIES, 1972). As auxinas endógenas, como o AIA (ácido indolacético), são sintetizadas nas regiões de crescimento - ápice caulinar, gemas e folhas (FIGUEIREDO et al., 1995; HINOJOSA, 2000).

\section{CONCLUSÕES}

De acordo com os resultados obtidos, conclui-se que:

a) O AIB apenas promoveu influência para as características pertinentes ao sistema radicular;

b) A concentração de $2000 \mathrm{mg} \mathrm{L}^{-1}$ de AIB promoveu maior porcentagem de enraizamento, independente da presença ou ausência de folhas; c) Para o número de raízes emitidas por estacas e comprimento médio das raízes, a concentração de 3000 mg $\mathrm{L}^{-1}$ de AIB em estacas com dois pares de folhas promoveu os melhores resultados;

d) Estacas ausentes de folhas favorecem maior brotação nas estacas.

\section{REFERÊNCIAS BIBLIOGRÁFICAS}

BIASI, L. A. Emprego do estiolamento na propagação de plantas. Ciência Rural, Santa Maria, v. 26, n. 2, p. 309-315, 1996.

CABALLERO, J. M. Multiplicación del olivo por etaquillado semileñoso bajo nebulización. Madrid: Instituto Nacional de Investigaciones Agrarias, 1981. 39 p. (Comunicaciones INIA, Serie Producción Vegetal, 31).

CABALleRO, J. M.; DEL RIO, C. Métodos de multiplicación. In: BARRANCO, D.; FÉRNADEZESCOBAR, R.; RALLO, L. (Eds.). El cultivo de olivo. 2. ed. Madri: Junta de Andalucia/Mundi-Prensa, 1998. p. 89-113.

CASTRO, C.; GUERREIRO, M.; CALDEIRA, F.; PINTO, P. Aspectos generales del sector oleícola em Portugal. Fruticultura Profesional, Barcelona, n. 88, p. 28-35, 1997. (Especial Olivicultura, 2).

FACHINELLO, J. C.; HOFFMANN, A.; NACHTIGAL, J. C.; KERSTEN, E.; FORTES, G. R. de L. Propagação de plantas frutíferas de clima temperado. 2. ed. Pelotas: UFPel, 1995. 178 p. 
FERREIRA, D. F. Análise estatística por meio do SISVAR (Sistema para Análise de Variância) para Windows versão 4.0. In: REUNIÃO ANUAL DA REGIÃO BRASILEIRA DA SOCIEDADE INTERNACIONAL DE BIOMETRIA, 45., 2000, São Carlos. Anais... São Carlos: UFSCar, 2000. p. 255-258.

FIGUEIREDO, S. L. B.; KERSTEN, E.; SCHUCH, M. W. Efeito do estiolamento parcial e do ácido indolbutírico (AIB) no enraizamento de estacas de goiabeira serrana (Feijoa sellowiana Berg). Scientia Agrícola, Piracicaba, v. 52, n. 1, p. 167-171, jan./abr. 1995.

GALSTON, A. W.; DAVIES, P. J. Mecanismo de controle no desenvolvimento vegetal. São Paulo: USP, 1972. 171 p.

GOBBATO, C. Cultura da oliveira e noções sobre a industrialização das azeitonas. Porto Alegre: Centro, 1945. 118 p.

GOMES, F. P. Curso de estatística experimental. 14. ed. Piracicaba: USP/ESALQ, 2000. 477 p.

HARTMANN, H. T.; KESTER, D. E.; DAVIES JUNIOR, F. T.; GENEVE, R. L. Plant propagation: principles and practices. 7. ed. New Jersey: Prentice Hall, 2002. 880 p.

HINOJOSA, G. F. Auxinas. In: CID, L. P. B. Introdução aos hormônios vegetais. Brasília: EMBRAPA, 2000. p. 15-54.

JACOBONI, N.; BATTAGLINI, M.; PERZIOSI, P. Propagación del olivo. In: . Olivicultura moderna. Madrid: FAO-INIA, 1976. p. 150-169.
MAYER, N. A. Propagação assexuada do portaenxerto umezeiro (Prunus mume Sieb \& Zucc.) por estacas herbáceas. 2001. 109 f. Dissertação (Mestrado em Produção Vegetal) - Faculdade de Ciências Agrárias e Veterinárias, Universidade Estadual Paulista, Botucatu, 2001.

MUNÕZ, H. I.; VALENZUELA, B. J. Enraizamento de la estacas herbáceas de três cultivares de videira: efecto de la ubicación en el sarmiento y época de recolección. Agricultura Técnica, Santiago, v. 38, n. 1, p.14-17, jan./mar. 1978.

NEGASH, L. Vegetative propagation of the threatened African wild olive [Olea europaea L. subsp cuspidata (Wall. ex DC.) Ciffieri]. New Forests, [S.l.], v. 26, n. 2, p. 137-146, Sept. 2003.

OLIVEIRA, A. F. de. Enraizamento de estacas semilenhosas e cultura de embriões in vitro de oliveira (Olea europaea L.). 2001. 122 p. Tese (Doutorado em Agronomia) - Universidade Federal de Lavras, Lavras, 2001.

PASQUAL, M.; CHALFUN, N. N. J.; RAMOS, J. D.; VALE, M. R. do; SILVA, C. R. de. R. e. Fruticultura comercial: propagação de plantas frutíferas. Lavras: UFLA/FAEPE, 2001. 137 p.

SEBASTIANI, L.; TOGNETTI, R. Growing season and hydrogen peroxide effects on root induction and development in Olea europaea L. (cvs 'Frantoio' and 'Gentile di Larino') cuttings. Scientia Horticulturae, Amsterdam, v. 100, n. 1-4, p. 75-82, Mar. 2004. 